\title{
MODIFICAÇÕE S CAUSADAS PELO USO E A FORMAÇÃO DE CAMADAS COMPACTADAS E, OU, ADENSADAS EM UM LATOSSOLO VERMELHO-ESCUROTEXTURA MÉDIA, NA REGIÃO DO CERRADO(1)
}

\author{
I. A. CARVALHO J ÚNIOR ${ }^{(2)}$, L. E. F. FONTES $S^{(3)} \&$ L. M. COSTA ${ }^{(3)}$
}

\begin{abstract}
RESUMO
O objetivo deste trabalho foi avaliar as modificações causadas pelos diferentes usos em atributos de um Latossolo de textura média e a influência destas na formação de camadas compactadas e, ou, adensadas de subsuperfície, sob diferentes usos agrícolas, na região do cerrado. Para tanto, em abril de 1994, nos municípios de Uberlândia e Monte Alegre de Minas, foram selecionados seis locais onde o solo foi amostrado em trincheiras: CC (Fazenda Canadá, vegetação de cerrado); CP (Fazenda Canadá, cultivo com uso de pi vô central); GC (Fazenda Gaia, vegetação de cerrado); GPa (Fazenda Gaia, pastagem); GP1 e GP2 (Fazenda Gaia, cultivo com uso de pivô central). 0 solo foi classificado como Latossolo Vermelho-Escuro, textura média e apresentava camadas compactadas e, ou, adensadas em subsuperfície, incluindo as áreas sob vegetação de cerrado, variando apenas o valor da densi dade do solo e a profundidade em que a camada aparece. $O$ cultivo provocou modificações em relação à presença do cerrado. A área sob pastagem, exceto por um aumento superficial na resistência à penetração, apresentou comportamento semel hante ao das áreas sob cerrado. 0 aumento da densidade nas camadas subsuperficiais deveu-se, possivelmente, ao aumento da argila dispersa em água nas áreas cultivadas. $\mathbf{O}$ aumento da argila dispersa em água ocorreu em decorrência de diversos fatores, tais como: redução do carbono orgânico, calagem e aumento do PCZ. Ocorreu correlação positiva e significativa entre o teor de $\mathrm{SiO}_{2}$ e a percentagem de argila dispersa em água e, conseqüentemente, com a formação de camadas compactadas e, ou, adensadas, no solo estudado, sob diferentes usos.
\end{abstract}

Termos de Indexação: compactação, adensamento, calagem, características físicas, características químicas.

(1) Parte da Tese de Mestrado do primeiro autor, apresentada ao Curso de Pós-Graduação em Solos e Nutrição de Plantas da Universidade Federal de Viçosa. Trabalho apresentado no XXV CBCS, em Viçosa (MG), 23-29 de julho de 1995. Recebido para publicação em junho de 1997 e aprovado em junho de 1998.

(2) Doutorando em Solos e Nutrição de Plantas, Universidade Federal de Viçosa - UFV. CEP 36571-000 Viçosa (MG).

(3) Professor Titular do Departamento de Solos, UFV. Bolsista do CNPq. 


\title{
SUMMARY: MODIFICATIONS CAUSED BY DIFFERENT AGRICULTURAL USES AND FORMATION OF COMPACTED AND, OR, DENSE LAYERS IN A DARK RED LATOSOL MEDIUM TEXTURE, IN THE CERRADO REGION OF BRAZIL
}

\begin{abstract}
The objective of this study was to evaluate the influence of different agricultural uses on alterations in the attributes of a medium-textured Latosol, in the regi on of cerrado and, in turn, on the formation of compacted and/ or dense layers in the subsurface In April, 1994, six sites weresel ected in the counties of U berlândia and M onteAlegredeMinas, State of Minas Gerais, Brazil, wherethesoil was sampled in trenches: CC (Canadá Farm, cerrado vegetation); CP ( Canadá Farm, cultivated with the use of a central pivot); GC (Gaia Farm, cerrado vegetation); GPa (Gaia Farm, pasture); GP1 and GP2 (Gaia Farm, cultivated with the use of a central pivot). The soil was classified as Dark Red Latosol of medium texture and presented compacted and, or, dense layers in the subsurface, even in the areas under cerrado vegetation, with variations only in the value of bulk density and depth in which these layers appear. The cultivation caused modifications in relation to the cerrado areas. The area under pasture presented a behaviour very similar to that of the cerrado areas, except for thehardening of thesurface Therewas an increasein density in thesubsuperficial layers, which may havebeen caused by theincrease of thewater-dispersed clay in thecultivated areas. Theincrease of thewater-dispersed day was caused by several factors, such as reduction of organic carbon and liming and increased PZC. There was a significant and positive correlation between $\mathrm{SiO}_{2}$ content and the percentage of water-dispersed clay, which contributed to the formation of compacted layers in this soil under different uses.
\end{abstract}

Index terms: Compaction, densing, li ming, physics characteristics, chemi cal characteristics.

\section{INTRODUÇÃO}

Nos cerrados, graças ao relevo pouco movimentado e a outras condições favoráveis, é intenso o uso de máquinas eimplementos agrícolas, com dois ou mais cultivos anuais, caso a irrigação seja incluída.

Esse tipo de manejo provoca modificações nas propriedades dos solos, em relação àquelas de seu estado natural. Tem sido detectada a presença de camadas compactadase, ou, adensadas subsuperficiais em sol os cultivados e, mesmo, sob vegetação natural.

A compactação dos solos é causada por uma intensa movimentação de máquinas e implementos agrícolas que provocam pressões na superfície do solo (Mantovani, 1987).

Alguns estudos mostram que a formação dessas camadas se dá pela eluviação de partículas finas para horizontes subsuperficiais, obstruindo os poros formados entre partículas maiores ou mi croagregados, ou seja, ocorre maior contato entre partículas, diminuindo a macroporosidade do solo (J ucksch, 1987).Tal processoécaracterizadocomo adensamento. A desagregação, no adensamento, é causada por modificações químicas, como a calagem (J ucksch, 1987), efísicas, provocadas por cidos de umedecimento esecagem (Oliveira, 1992). As princi pais causas, que podem ser naturais ou antrópicas, são a chuva e os dispersantes químicos, que desagregam parcialmente osolo, levandoà dispersão das partículas sólidas, além da desagregação mecânica, com enxada rotativa e grades.
São inúmeros os trabal hos que avaliam o efeito do cultivo e de sistemas de preparo sobre as diversas propriedades dos sol os. Eltz et al. (1989) concluíram que manejos diferentes modificam o tamanho dos agregados estáveis de um Latossolo. A mesma conclusãofoi obtida por Paladini \& Mielniczuk (1991) para Podzólicos.

É importante observar quea maioria dos estudos apenas analisa as conseqüências dos diferentes manejos, mas são raras as pesquisas que estudam as modificações de propriedades químicas ou físicas dos sol os, tentando explicar a formação das camadas compactadase, ou, adensadas frenteaos diversos usos.

Este trabalho teve como objetivo avaliar a influência de diferentes usos de máquinas e implementos agrícolas nas propriedades físicas e químicas de um Latossolo de textura média, na região do cerrado, com intuito de obter informações sobre o efeito destes na formação de camadas compactadas e adensadas em subsuperfície.

\section{MATERIAL E MÉTODOS}

Os materiais de solos estudados foram provenientes das fazendas Canadá e Gaia da Empresa ABC A \& P-S.A. A primeira, situada no município de Uberlândia, cuja latitude e longitude aproximadas são $18^{\circ} 55^{\prime}$ sul e $48^{\circ} 17^{\prime}$ oeste, respectivamente. A segunda, localizada no município de Monte Alegre 
deMinas, cuja latitudee longitudeaproximadas são $18^{\circ} 52^{\prime}$ sul e $48^{\circ} 52^{\prime}$ oeste, respectivamente. Os municípios Iocalizam-se na região do Triângulo Mineiro, Estado de Minas Gerais. A área pertence à Bacia do Rio Paraná, com altitude média entre 850 e 900 metros. O relevo é suave ondulado. O clima da região foi classificado como Aw, pelo Sistema de Köppen. Apresenta inverno frio e seco e verão quente e chuvoso (entre os meses de outubro e março). A precipitação total anual é de 1.400 a $1.500 \mathrm{~mm}$. A temperatura média anual está entre 20 e $24^{\circ} \mathrm{C}$, variando de $18^{\circ} \mathrm{C}$, para o mês mais frio, e $25^{\circ} \mathrm{C}$, para o mês mais quente. $A$ vegetação característica da área é o cerrado. O material de origem dos sol os estudados é proveniente, predominantemente, de arenitos da Formação Bauru.

\section{Trabalho de campo}

Após percorrer e observar a área, foram selecionados seis pontos para abertura das trincheiras, considerando o tipo de uso e manejo ea representatividade do local; duas na Fazenda Canadá e quatro na Fazenda Gaia. Abriram-se trincheiras com $1 \mathrm{~m}$ de largura e comprimento e $0,5 \mathrm{~m}$ de profundidade. As amostras de solos foram coletadas em setembro de 1993, após a col heita e antes do preparo dos solos a serem cultivados. As trincheiras em estudo foram denominadas: CC, CP, GC, GPa, GP1 e GP2. O solo foi classificado como Latossol o Vermelho-E scuro textura média. A cor do solo é vermelho (2,5 YR 4/6 úmido amassado) e vermel ho (3,5 YR 4/6 úmido), avaliada na trincheira GPa. Fez-se um diagnóstico no local da col eta sobre a condição física do solo em cada trincheira. Utilizaram-se faca e martelo pedológico, para observar a resistência à penetração, e piseta, para avaliar a vel oci dade de infiltração de água, a fim de se verificar, em campo, a presença de camadas compactadas e, ou, adensadas.

\section{Características das trincheiras e das áreas}

CC - representou solo da fazenda Canadá (C) sob vegetação de cerrado (C); CP - representou solo da Fazenda Canadá (C), sob cultivo de milho e soja (rotação de cultura) desde 1987, irrigado por pivô central $(P)$. O preparo do solo era feito com grade niveladora e arado de disco, anualmente. Houve incorporação de milheto em 1991; GC - representou solo da Fazenda Gaia (G) sob cerrado (C); GPa representou sol o da Fazenda Gaia (G) sob pastagem de braquiária, desde 1986 (Pa). A pastagem encontrava-seem bom estado. A área encontrava-se em cotas altimétricas mais baixas entre todas as estudadas, e o solo era mais amarelado; GP 1 representou solo da Fazenda Gaia (G), sob cultivo de milho desde 1987, irrigado por pivô central (P1). O preparo do solo era feito com grade pesada. A área era terraceada e apresentava sérios problemas de erosão; GP2 - representou sol o da Fazenda Gaia (G), sob cultivo de feijão e soja em rotação desde 1979, irrigado por pivô central (P2). Na época da coleta, o feijão estava em fim de ciclo. O preparo do solo era feito com arado de discos.

\section{Coleta do material de solo}

Para as análises de laboratório, coletaram-se amostras deformadas e indeformadas, em camadas de $0-0,025 ; 0,025-0,05 ; 0,05-0,075 ; 0,075-0,10 ; 0,10-0,15$; $0,15-0,20 ; 0,20-0,30$ e $0,30-0,40 \mathrm{~m}$ de profundidade, perfazendo um total de oito profundidades para cada trincheira. Para as amostras deformadas, o material foi seco ao ar e passado em peneira com malhas de $0,002 \mathrm{~m}$. O material indeformado foi coletado em torrões e seco ao ar.

\section{Análises físicas}

Foram realizadas análise textural, pelo método da pi peta, densidade do solo, pel o método do torrão parafinado, e densidade de partículas, pelo método do balãovol umétrico, tendoál cool etílico como líquido penetrante (E MBRAPA, 1979). Porosidade total foi calculada pela expressão: porosidade total $\left(\mathrm{m}^{3} \mathrm{~m}^{-3}\right)=$ $100 \times$ (densidade real - densidade do solo)/densidade real. Para verificar a argila dispersa em água, utilizou-seagitador horizontal de 200 oscilações por minuto, segundo J ucksch (1987). Para obter o número de repetições necessárias para argila dispersa em água, foram segui das as recomendações de Farias et al. (1991). Grau de floculação foi cal culado pela expressão: grau defloculação $(\%)=100$ x (argila total - argila dispersa emágua)/argila total.

\section{Análises químicas}

Reação do solo: foram determinados pH em água e em KCl 1 mol L-1, na relação 1:2,5, de acordo com EMBRAPA (1979); carbono orgânico: feito pelo método Walkley-Black, conforme J ackson (1958), citado por Defelipo \& Ribeiro (1981); ponto de Carga Zero (PCZ); realizado em três profundidades para cada trincheira, 0-0,025, 0,10-0,15 e 0,30-0,40 m, exceto para a trincheira GP1, com as profundidades de 0-0,025, 0,075-0,10 e 0,20-0,30 m. Utilizou-se o método titulométrico, de acordo com Costa et al . (1984); cátions trocáveis, Ca2+e Mg2+, extraídos com $\mathrm{KCl} 1 \mathrm{~mol} \mathrm{~L}^{-1}$, e $\mathrm{K}^{+}$, como extrator Mehlich- $1 / \mathrm{K}^{+}$, conforme Defelipo \& Ribeiro (1981); alumínio trocável, extraído com KCl 1 mol L-1 (Raij et al., 1981); acidez potencial, extraída com $\mathrm{Ca}(\mathrm{OAc})_{2}$ 0,5 mol L-1 a pH 7,0 conformeVettori (1969); ataque sulfúrico, realizado de acordo com E MBRAPA (1979), analisando-se $\mathrm{Fe}, \mathrm{Al}, \mathrm{Si}, \mathrm{Ti}$ e $\mathrm{P}$, expressos, respectivamente, como $\mathrm{Fe}_{2} \mathrm{O}_{3}, \mathrm{Al}_{2} \mathrm{O}_{3}, \mathrm{SiO}_{2}, \mathrm{TiO}_{2}$ e $\mathrm{P}_{2} \mathrm{O}_{5}$, para três profundidades de cada trincheira, selecionando-se uma camada superior euma inferior à camada adensada, e uma referente à camada adensada e, ou, compactada, sel ecionada a partir dos dados de densidade do solo.

\section{Análises estatísticas}

Os dados foram submetidos à análise estatística, pel oestudo da correlação dePearson. Consideraram-se 
seis trincheiras e oito profundidades, perfazendo um total de 48 observações para cada variável, com exceção do PCZ e dos valores de ataque sulfúrico, com menor número de observações.

\section{RESULTADOS E DISCUSSÃO}

\section{Caracterização física dos solos em profundidade}

Considerando os resultados da análise textural, da argila dispersa em água e do grau de floculação (Quadro 1), observa-se que os solos são bastante arenosos, variando de 720 a $830 \mathrm{~g} \mathrm{~kg}^{-1}$ deareia total. Os teores de silte e de argila total variaram de 20 a 90 e de 110 a $210 \mathrm{~g} \mathrm{~kg}^{-1}$, respectivamente. A variação de solo entre trincheiras não foi tão expressiva; todavia, dentro da própria trincheira, observaramse variações mais perceptíveis das frações texturais.

\section{Diagnóstico efetuado no campo}

De acordo com o diagnóstico feito em campo e com as análises de laboratório (Figura 1), todos os solos apresentaram camadas adensadas em subsuperfície, independentemente do uso, variando apenas a intensidade. Os solos, na época da coleta, apresentavam-se secos, aumentando um pouco a

Quadro 1. Resultados das análises de areia grossa (AG), areia fina (AF), silte (SL), argila total (ARGT), argila dispersa em água (ARGD), grau de floculação (GF), densidade de partículas (DR) e porosidade total (PT) para as seis trincheiras estudadas

\begin{tabular}{|c|c|c|c|c|c|c|c|c|c|}
\hline Solo & Profundidade & AG & AF & SL & ARGT & ARGD & GF & DR & PT \\
\hline & $\mathrm{m}$ & $\longrightarrow$ & 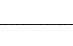 & $\mathrm{g} \mathrm{kg}^{-1}$ & 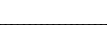 & - & $\mathrm{m}^{3} \mathrm{~m}^{-3}$ & $\mathrm{~kg} \mathrm{dm}^{-3}$ & $m^{3} m^{-3}$ \\
\hline $\mathrm{CC}$ & $\begin{array}{l}0-0,025 \\
0,025-0,05 \\
0,05-0,075 \\
0,075-0,10 \\
0,10-0,15 \\
0,15-0,20 \\
0,20-0,30 \\
0,30-0,40\end{array}$ & $\begin{array}{l}400 \\
340 \\
350 \\
360 \\
330 \\
370 \\
320 \\
370\end{array}$ & $\begin{array}{l}420 \\
410 \\
410 \\
410 \\
450 \\
380 \\
430 \\
350\end{array}$ & $\begin{array}{l}40 \\
50 \\
70 \\
70 \\
60 \\
50 \\
60 \\
70\end{array}$ & $\begin{array}{l}140 \\
200 \\
170 \\
160 \\
160 \\
200 \\
190 \\
210\end{array}$ & $\begin{array}{l}26 \\
29 \\
26 \\
39 \\
39 \\
44 \\
39 \\
38\end{array}$ & $\begin{array}{l}82 \\
86 \\
85 \\
76 \\
76 \\
77 \\
79 \\
82\end{array}$ & $\begin{array}{l}2,53 \\
2,52 \\
2,55 \\
2,55 \\
2,52 \\
2,52 \\
2,55 \\
2,55\end{array}$ & $\begin{array}{l}0,45 \\
0,46 \\
0,51 \\
0,44 \\
0,45 \\
0,43 \\
0,39 \\
0,44\end{array}$ \\
\hline$C P$ & $\begin{array}{l}0-0,025 \\
0,025-0,05 \\
0,05-0,075 \\
0,075-0,10 \\
0,10-0,15 \\
0,15-0,20 \\
0,20-0,30 \\
0,30-0,40\end{array}$ & $\begin{array}{l}380 \\
370 \\
410 \\
380 \\
420 \\
350 \\
360 \\
380\end{array}$ & $\begin{array}{l}450 \\
440 \\
400 \\
440 \\
380 \\
450 \\
420 \\
400\end{array}$ & $\begin{array}{l}20 \\
30 \\
30 \\
20 \\
30 \\
30 \\
20 \\
40\end{array}$ & $\begin{array}{l}150 \\
160 \\
160 \\
160 \\
170 \\
170 \\
200 \\
180\end{array}$ & $\begin{array}{l}46 \\
66 \\
59 \\
56 \\
58 \\
52 \\
55 \\
54\end{array}$ & $\begin{array}{l}69 \\
60 \\
63 \\
65 \\
66 \\
69 \\
72 \\
71\end{array}$ & $\begin{array}{l}2,55 \\
2,55 \\
2,55 \\
2,53 \\
2,56 \\
2,56 \\
2,55 \\
2,56\end{array}$ & $\begin{array}{l}0,38 \\
0,37 \\
0,35 \\
0,31 \\
0,32 \\
0,34 \\
0,36 \\
0,33\end{array}$ \\
\hline GC & $\begin{array}{l}0-0,025 \\
0,025-0,05 \\
0,05-0,075 \\
0,075-0,10 \\
0,10-0,15 \\
0,15-0,20 \\
0,20-0,30 \\
0,30-0,40\end{array}$ & $\begin{array}{l}390 \\
360 \\
380 \\
350 \\
400 \\
370 \\
360 \\
360\end{array}$ & $\begin{array}{l}410 \\
440 \\
410 \\
430 \\
400 \\
450 \\
460 \\
430\end{array}$ & $\begin{array}{l}30 \\
30 \\
40 \\
40 \\
30 \\
30 \\
30 \\
40\end{array}$ & $\begin{array}{l}170 \\
170 \\
170 \\
180 \\
170 \\
150 \\
150 \\
170\end{array}$ & $\begin{array}{l}19 \\
35 \\
34 \\
43 \\
36 \\
32 \\
33 \\
41\end{array}$ & $\begin{array}{l}89 \\
80 \\
80 \\
76 \\
79 \\
79 \\
78 \\
76\end{array}$ & $\begin{array}{l}2,56 \\
2,57 \\
2,58 \\
2,58 \\
2,58 \\
2,58 \\
2,55 \\
2,57\end{array}$ & $\begin{array}{l}0,48 \\
0,41 \\
0,47 \\
0,40 \\
0,36 \\
0,40 \\
0,44 \\
0,50\end{array}$ \\
\hline $\mathrm{GPa}$ & $\begin{array}{l}0-0,025 \\
0,025-0,05 \\
0,05-0,075 \\
0,075-0,10 \\
0,10-0,15 \\
0,15-0,20 \\
0,20-0,30 \\
0,30-0,40\end{array}$ & $\begin{array}{l}500 \\
530 \\
530 \\
430 \\
520 \\
540 \\
570 \\
510\end{array}$ & $\begin{array}{l}310 \\
300 \\
290 \\
370 \\
280 \\
280 \\
230 \\
300\end{array}$ & $\begin{array}{l}20 \\
50 \\
70 \\
70 \\
90 \\
40 \\
40 \\
40\end{array}$ & $\begin{array}{l}170 \\
120 \\
110 \\
130 \\
110 \\
140 \\
160 \\
150\end{array}$ & $\begin{array}{l}7 \\
21 \\
21 \\
22 \\
21 \\
19 \\
25 \\
21\end{array}$ & $\begin{array}{l}96 \\
82 \\
82 \\
84 \\
82 \\
87 \\
84 \\
86\end{array}$ & $\begin{array}{l}2,51 \\
2,51 \\
2,54 \\
2,54 \\
2,54 \\
2,55 \\
2,55 \\
2,55\end{array}$ & $\begin{array}{l}0,46 \\
0,51 \\
0,50 \\
0,52 \\
0,41 \\
0,40 \\
0,41 \\
0,48\end{array}$ \\
\hline GP 1 & $\begin{array}{l}0-0,025 \\
0,025-0,05 \\
0,05-0,075 \\
0,075-0,10 \\
0,10-0,15 \\
0,15-0,20 \\
0,20-0,30 \\
0,30-0,40\end{array}$ & $\begin{array}{l}440 \\
430 \\
450 \\
420 \\
450 \\
460 \\
480 \\
410\end{array}$ & $\begin{array}{l}370 \\
380 \\
360 \\
380 \\
360 \\
360 \\
320 \\
370\end{array}$ & $\begin{array}{l}30 \\
30 \\
30 \\
40 \\
30 \\
30 \\
30 \\
50\end{array}$ & $\begin{array}{l}160 \\
160 \\
160 \\
160 \\
160 \\
150 \\
170 \\
170\end{array}$ & $\begin{array}{l}57 \\
34 \\
48 \\
37 \\
52 \\
57 \\
56 \\
62\end{array}$ & $\begin{array}{l}64 \\
79 \\
71 \\
76 \\
69 \\
64 \\
67 \\
64\end{array}$ & $\begin{array}{l}2,47 \\
2,44 \\
2,43 \\
2,45 \\
2,43 \\
2,44 \\
2,47 \\
2,47\end{array}$ & $\begin{array}{l}0,43 \\
0,38 \\
0,36 \\
0,31 \\
0,31 \\
0,31 \\
0,34 \\
0,38\end{array}$ \\
\hline GP 2 & $\begin{array}{l}0-0,025 \\
0,025-0,05 \\
0,05-0,075 \\
0,075-0,10 \\
0,10-0,15 \\
0,15-0,20 \\
0,20-0,30 \\
0,30-0,40\end{array}$ & $\begin{array}{l}510 \\
480 \\
470 \\
490 \\
460 \\
470 \\
490 \\
480\end{array}$ & $\begin{array}{l}320 \\
320 \\
300 \\
300 \\
330 \\
340 \\
300 \\
300\end{array}$ & $\begin{array}{l}30 \\
30 \\
60 \\
50 \\
30 \\
50 \\
30 \\
40\end{array}$ & $\begin{array}{l}140 \\
170 \\
170 \\
160 \\
180 \\
140 \\
180 \\
180\end{array}$ & $\begin{array}{l}47 \\
57 \\
48 \\
59 \\
64 \\
61 \\
70 \\
70\end{array}$ & $\begin{array}{l}72 \\
67 \\
71 \\
63 \\
65 \\
58 \\
61 \\
61\end{array}$ & $\begin{array}{l}2,59 \\
2,59 \\
2,59 \\
2,58 \\
2,59 \\
2,58 \\
2,58 \\
2,59\end{array}$ & $\begin{array}{l}0,33 \\
0,31 \\
0,34 \\
0,31 \\
0,35 \\
0,33 \\
0,37 \\
0,42\end{array}$ \\
\hline
\end{tabular}




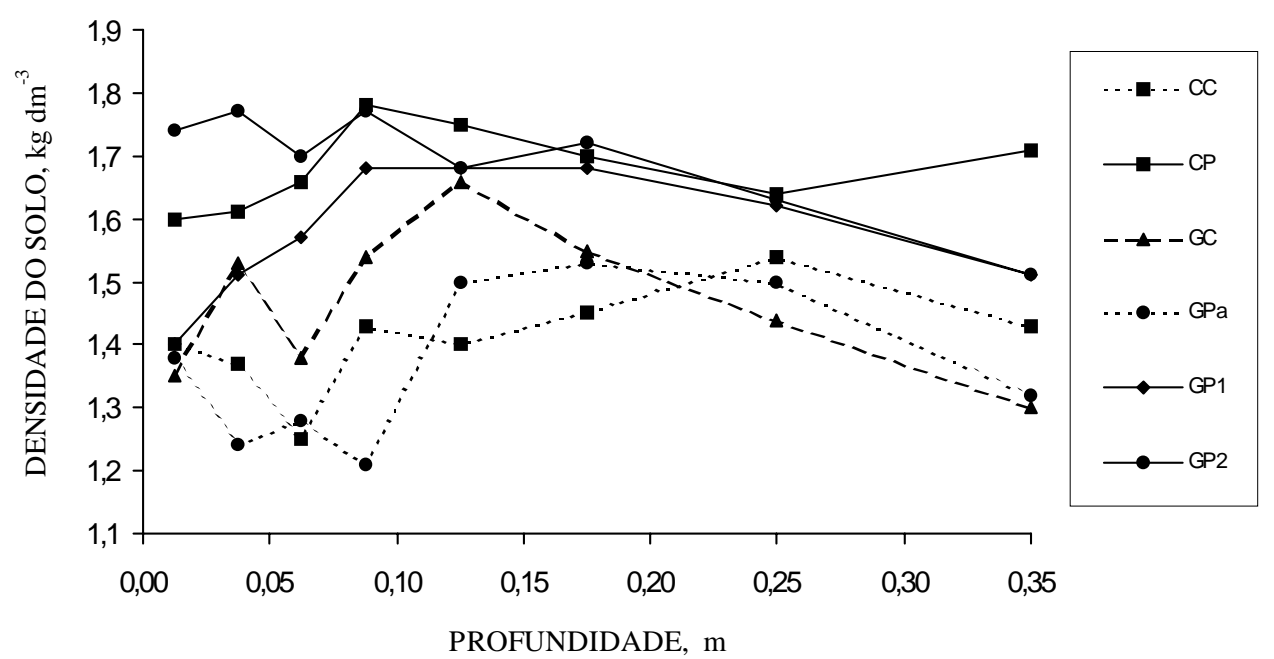

Figura 1. Densidade do solo para as seis trincheiras estudadas.

umidade em profundidade. CC - Pela descrição de campo, esta trincheira apresentou camada adensada entre 0,05 e 0,30 m, sendo mais resistente à penetração entre 0,10 e 0,15 m. Pelas análises de laboratório, a camada adensada localizava-se entre 0,20 e 0,30 m de profundidade (Figura 1). Continha grande quantidade de restos orgânicos, não havendo problema de infiltração de água, tampouco impedimento ao crescimento deraízes. CP - A camada compactada foi percebida entre 0,10 e 0,30 m de profundidade, pela descrição de campo. Pelas análises de laboratório, ela se situava entre 0,075 e $0,20 \mathrm{~m}$ de profundidade, com val ores mais el evados quea da trincheira anterior (F igura 1). Essa camada apresentava baixa infiltração de água, era resistente à penetração e parecia ser um impedimento ao crescimento das raízes. GC - Pela descrição de campo, a camada adensada apresentou-se entre 0,20 e 0,30 m. Pelas análises de laboratório, a camada adensada estava entre 0,075 e0,20 m deprofundidade (Figura 1). As outras características eram semel hantes às da CC. GPa - revelava condição diferente das outras, por apresentar um encrostamento superficial, possivelmente em virtude do pisoteio do gado. A camada adensada apresentou-se entre 0,05 e 0,15 m de profundidade, pelo diagnóstico de campo. Pelas análises de laboratório, a camada adensada estava entre 0,10 e 0,30 m de profundidade (Figura 1), porém os valores de densidade do solo não foram altos o suficiente para causar impedimento ao crescimento radicular. Apresentou uma alta densidade de raízes, principalmente até $0,30 \mathrm{~m}$ de profundidade. $\mathrm{O}$ valor da densidade do solo foi relativamente baixo para a camada superficial, com encrostamento superficial, talvez por ter a espessura da amostra $(0-0,025 \mathrm{~m})$ reduzi do seu val or a um val or médio mais baixo, já que a referida camada era bastante fina. GPI - Pela descrição de campo, essa trincheira apresentava uma camada bastante dura entre 0,10 e 0,30 m. A camada compactada estava entre 0,075 e 0,20 m de profundidade, pelas análises de laboratório (Figura 1), revelando problemas de infiltração de água e impedimento ao crescimento de raízes, o que pode explicar os sérios problemas de erosão, mesmo em áreas terraceadas. GP2 - A camada compactada apresentou-se entre 0,15 e 0,40 m de profundidade, pela descrição de campo, sendo bastante resistente à penetração. Pelas análises de laboratório, a camada compactada ocorreu entre 0 e 0,20 m de profundidade(Figura 1 ). A infiltração de água foi baixa nessa camada. Os valores de densidade do solo foram bastante elevados, mas, considerando ser a textura arenosa (Figura 1), justificam-se os altos valores da densidade do solo. Percebeu-se em campo que, a partir de valores de 1,60 kg dm-3, aproximadamente, surgiram problemas para o desenvolvimento radicular das plantas e infiltração da água.

Um pontoa ser mencionadoéa profundidadeem que apareceu a camada adensada e, ou, compactada. Nas trincheiras deáreas com vegetação natural, essa camada situava-se entre 0,20 e 0,30 e 0,075 e 0,20 m de profundidade para CC e GC, respectivamente. Para GPa, estava entre 0,10 e 0,30 m. Para as áreas cultivadas, variava de 0,075 a 0,20 m para CP eGP 1 e 0 a $0,20 \mathrm{~m}$ para GP2. De maneira geral, não se observou tal problema além de $0,30 \mathrm{~m}$ de profundidade, mas existia desde a superfície, normalmente a partir de $0,075 \mathrm{~m}$ de profundidade. I sto mostra que o problema não é só o pé-de-grade ou pé-de-arado, contrariando as conclusões de Alvarenga et al. (1987), já que a profundidade de revol vimento nesses solos é de $0,20 \mathrm{~m}$, eas camadas compactadas e, ou, adensadas ultrapassaram, acima e abaixo, esse limite. Além disso, observou-se a presença dessas camadas em solos sob vegetação natural e sob pastagem, onde não se utilizavam máquinas há pelo menos seis anos antes da col eta. 


\section{Uso do solo, propriedades físicas e camadas adensadas e, ou, compactadas}

Os diferentes usos do solo provocaram mudanças nítidas em suas propriedades físicas e químicas. No caso das propriedades físicas, houve aumento da densidade do solo (Figura 1) devido à redução da porosidade total (Quadro 1) nas áreas cultivadas e irrigadas com pivô central (CP, GP1, GP2), em comparação com as áreas sob vegetação natural (CC eGC).A área sob pastagem (GPa) tevecomportamento distinto das outras, apresentando val ores semel hantes aos da área sob vegetação natural, tendo apenas encrostamento superficial, que a profundidade de amostragem utilizada para determinação da densidade do sol o não foi adequada para detectar.

Outros atri butos quetambém foram nitidamente modificados pel o cultivo foram a argila dispersa em água e o grau de floculação (Quadro 1). As áreas cultivadas apresentaram nítido aumento da primeira e conseqüente diminuição da segunda, em relação às áreas sob vegetação natural e sob pastagem, que manifestaram, em al guns casos, maior grau de floculação que a área sob vegetação de cerrado. Resultados semel hantes for am encontrados por Eltz et al . (1989) e Paladini \& Mielniczuk (1991).

A modificação desses atributos foi importante para explicar a formação das camadas compactadas e, ou, adensadas. O coeficiente de correlação com a densidade do solo foi de 0,6898 e de -0,6823, para argila dispersa em água e grau de floculação, respectivamente, ambos significativos a $1 \%$. 0 aumento da argila dispersa, resultado da destrui ção parcial dos agregados e da redução do estado de agregação dos sol os, levou à eluviação das partículas dispersas. Isto, provavel mente, facilitou o novo arranjo de partículas e maior adensamento nessas camadas, gerando aumento na densidade do solo. Fonseca (1986) justificou o alto estado de adensamento dos solos desenvolvidos nos sedimentos do Barreiras pela baixa estabilidade dos agregados e pela alta dispersão de argilas encontradas nesses solos. De acordo com Baver et al. (1973), há um rearranjo das partículas do solo que setraduz em al terações na distribuição dos poros por tamanho e diminuição da porosidade total.

\section{Uso do solo, propriedades químicas e camadas adensadas e, ou, compactadas}

A argila dispersa em água aumentou com o cultivo por diversos fatores. Esperava-se que o aumento da carga líquida do solo acarretasse o aumento da argila dispersa (Costa et al., 1984). A matéria orgânica (Quadro 2) mostrou um coeficiente de correlação negativo com a argila dispersa de $-0,6217$, significativo a $1 \%$, ou seja, o aumento de matéria orgânica (MORG) provocou a di minuição da argila dispersa. Isto parece contraditório, já que a MORG deveria contribuir com cargas para esses sol os, mas pode haver mudanças na qualidade desta MORG. Os solos sob vegetação natural, apesar de apresentarem mais MORG, provavelmente a apresentaram em forma mais humificada, tendo um efeito de cimentação bem mais pronunciado que o de dispersão pel o aumento da carga líquida. O efeito da matéria orgânica de aumentar a agregação e o tamanho dos agregados foi encontrado por Paladini \& Mielniczuk (1991) e Roth et al. (1991). O solo sob pastagem, da mesma maneira que os que se encontravam sob vegetação natural , apesar de conter al to teor de MORG, por ser formado a partir de gramíneas, deveria ser mais humificado. Por isso, o solo sob pastagem, em al guns casos, apresentou um grau de floculação maior que os sol os sob vegetação natural (Quadro 1). Bradifield (1937), citado por Paladini \& Mielniczuk (1991), afirmou que as gramíneas, pelo seu sistema radicular extenso e em constante renovação, são eficientes na agregação do solo.

A calagem foi outra atividade que causou algumas modificações nos solos cultivados. No quadro 2, pode-se perceber que o $\mathrm{pH}$ em $\mathrm{H}_{2} \mathrm{O}$ e o $\mathrm{pH}$ em $\mathrm{KCl}$ aumentaram em virtude da calagem, nos solos cultivados, da mesma maneira que a acidez trocável $\left(\mathrm{Al}^{3+}\right)$ e potencial $(\mathrm{H}+\mathrm{Al})$ diminuíram, e os teores de $\mathrm{Ca}^{2+}$ e $\mathrm{Mg}^{2+}$ (Quadro 3) aumentaram. O teor de K+também aumentou e, conseqüentemente, a soma de bases (SB), já que, conjuntamente com a calagem, fizeram-se outras adubações. Todas essas variáveis influenciaram, de maneira consistente, a formação das camadas compactadas e, ou, adensadas, princi palmente pel o aumento da argila dispersa em água, causado por este desbalanço de cargas, nas áreas que receberam calagem, fato verificado por Fernandes (1996), Gomes (1996) eJ ucksch (1987).

O aumento do $\mathrm{pH}$ em $\mathrm{H}_{2} \mathrm{O}$ e do $\mathrm{pH}$ em $\mathrm{KCl}$ resulta em um aumento de cargas nesses solos que, por serem Latossol os, são formados por minerais do tipo óxidos de Fe e Al e caulinita, tendo como tipos de cargas, principalmente, as dependentes de $\mathrm{pH}$. O aumento de cargas nos solos cultivados devido à calagem pode provocar um aumento da argila dispersa em água, levando à formação das camadas adensadas. Tal efeito é mostrado pel os coeficientes de correlação e níveis de significância apresentados no quadro 4.

A acidez trocável e a potencial, que diminuíram com a calagem, também influenciaram a formação das camadas compactadas e, ou, adensadas. A acidez trocável e a potencial medem o $\mathrm{Al}^{3+}$ e o $\mathrm{H}+\mathrm{Al}$, respectivamente, ambos cátions floculantes, comparados às bases trocáveis. Então, a redução desses cátions em relação às bases trocáveis levaria a um aumento da dispersão de argila que, por sua vez, pode provocar aumento da densidade do solo, pela eluviação e preenchimento dos poros. O quadro 4 mostra a correlação desses fatores com a argila dispersa em água e com a densidade do solo. 
O efeito das bases trocáveis (Quadro 3) neste fenômeno podeser analisado no quadro 4. 0 aumento do $\mathrm{Ca}^{2+}$ e $\mathrm{Mg}^{2+}$ trocáveis e a correspondente diminuição de $\mathrm{Al}^{3+}$ e $\mathrm{H}^{+}$trocáveis promovem a expansão da dupla camada difusa e, conseqüentemente, o aumento da argila dispersa em água. Outro efeito destas bases é que elas geram um aumento de cargas elétricas líquidas do solo, o que também pode levar a um aumento da argila dispersa. Fica claro, quando se observa o quadro 4, queK+teve correlação não-significativa com a argila dispersa e com a densidade do solo. I sto talvez tenha se dado pel o baixo teor deste em relação ao $\mathrm{Ca}^{2+} \mathrm{e} \mathrm{Mg}^{2+}$, que contribuíram muito mais para a soma de bases, principalmente o cál cio.
Todas estas variáveis influenciam, de maneira conjunta, as propriedades do sol o. O aumento do pH significa uma redução da acidez trocável e da potencial e um aumento das bases trocáveis. Essa melhoria da condi ção química causou problemas nas propriedades físicas, princi pal mente no que se refere à argila dispersa em água.

O solo sob pastagem teve um comportamento singular em rel ação aos demais. Suas condi ções físicas são semel hantes às do sol o sob vegetação natural e as condições químicas, por outro lado, semel hantes às do sol o cul tivado com uso de pivô central. O teor de MORG desses solos se apresentou alto em relação aos cultivados e, em al guns casos, também em rel ação aos sob vegetação natural. Em campo, percebeu-se

Quadro 2. Resultados de análises de matéria orgânica (MORG), pH em água e em $\mathrm{KCl}$, acidez trocável, acidez potencial e PCZ para as seis trincheiras estudadas

\begin{tabular}{|c|c|c|c|c|c|c|c|}
\hline Solo & Profundidade & MORG & $\mathrm{pH}\left(\mathrm{H}_{2} \mathrm{O}\right)$ & $\mathrm{pH}(\mathrm{KCl})$ & Acidez trocável & Acidez potencial & PCZ \\
\hline & $\mathrm{m}$ & $\mathrm{g} \mathrm{kg}^{-1}$ & & \multicolumn{4}{|c|}{$-\mathrm{cmol}_{\mathrm{c}} \mathrm{dm}^{-3}$ de solo - } \\
\hline $\mathrm{CC}$ & $\begin{array}{l}0-0,025 \\
0,025-0,05 \\
0,05-0,075 \\
0,075-0,10 \\
0,10-0,15 \\
0,15-0,20 \\
0,20-0,30 \\
0,30-0,40\end{array}$ & $\begin{array}{l}35,1 \\
29,4 \\
25,3 \\
19,3 \\
20,0 \\
14,8 \\
13,6 \\
14,1\end{array}$ & $\begin{array}{l}4,40 \\
4,45 \\
4,50 \\
4,55 \\
4,60 \\
4,60 \\
4,65 \\
4,70\end{array}$ & $\begin{array}{l}3,90 \\
4,10 \\
4,05 \\
4,15 \\
4,15 \\
4,20 \\
4,20 \\
4,25\end{array}$ & $\begin{array}{l}1,25 \\
1,55 \\
1,05 \\
0,85 \\
0,65 \\
0,75 \\
3,99 \\
3,00\end{array}$ & $\begin{array}{l}6,33 \\
5,01 \\
4,32 \\
3,66 \\
3,99 \\
3,66 \\
0,65 \\
0,75\end{array}$ & $\begin{array}{l}4,25 \\
3,90 \\
4,16\end{array}$ \\
\hline $\mathrm{CP}$ & $\begin{array}{l}0-0,025 \\
0,025-0,05 \\
0,05-0,075 \\
0,075-0,10 \\
0,10-0,15 \\
0,15-0,20 \\
0,20-0,30 \\
0,30-0,40\end{array}$ & $\begin{array}{l}22,4 \\
21,7 \\
20,5 \\
20,0 \\
16,0 \\
16,0 \\
16,0 \\
11,4\end{array}$ & $\begin{array}{l}5,30 \\
5,50 \\
5,30 \\
5,70 \\
6,00 \\
5,95 \\
6,00 \\
6,00\end{array}$ & $\begin{array}{l}4,70 \\
4,85 \\
4,75 \\
5,10 \\
5,30 \\
5,25 \\
5,35 \\
5,35\end{array}$ & $\begin{array}{l}0,25 \\
0,25 \\
0,05 \\
0,00 \\
0,00 \\
0,00 \\
0,00 \\
0,00\end{array}$ & $\begin{array}{l}5,01 \\
2,34 \\
2,67 \\
2,01 \\
1,32 \\
1,32 \\
0,99 \\
0,99\end{array}$ & $\begin{array}{l}4,35 \\
4,52\end{array}$ \\
\hline GC & $\begin{array}{l}0-0,025 \\
0,025-0,05 \\
0,05-0,075 \\
0,075-0,10 \\
0,10-0,15 \\
0,15-0,20 \\
0,20-0,30 \\
0,30-0,40\end{array}$ & $\begin{array}{l}48,3 \\
48,3 \\
44,2 \\
25,3 \\
24,3 \\
26,0 \\
17,9 \\
11,0\end{array}$ & $\begin{array}{l}4,50 \\
4,25 \\
4,30 \\
4,30 \\
4,35 \\
4,35 \\
4,55 \\
4,55\end{array}$ & $\begin{array}{l}3,95 \\
3,95 \\
3,90 \\
3,90 \\
3,95 \\
3,85 \\
4,10 \\
4,05\end{array}$ & $\begin{array}{l}1,35 \\
1,55 \\
1,35 \\
1,25 \\
1,15 \\
1,35 \\
1,25 \\
0,75\end{array}$ & $\begin{array}{l}8,01 \\
7,68 \\
6,33 \\
7,32 \\
6,99 \\
5,67 \\
3,99 \\
3,66\end{array}$ & $\begin{array}{l}3,87 \\
3,77 \\
3,90\end{array}$ \\
\hline $\mathrm{GPa}$ & $\begin{array}{l}0-0,025 \\
0,025-0,05 \\
0,05-0,075 \\
0,075-0,10 \\
0,10-0,15 \\
0,15-0,20 \\
0,20-0,30 \\
0,30-0,40\end{array}$ & $\begin{array}{l}49,0 \\
40,8 \\
33,2 \\
31,8 \\
26,1 \\
27,2 \\
30,6 \\
25,1\end{array}$ & $\begin{array}{l}6,15 \\
5,95 \\
5,95 \\
5,80 \\
5,75 \\
5,85 \\
5,90 \\
5,85\end{array}$ & $\begin{array}{l}5,15 \\
5,05 \\
5,05 \\
5,00 \\
5,10 \\
5,20 \\
5,25 \\
5,35\end{array}$ & $\begin{array}{l}0,00 \\
0,05 \\
0,05 \\
0,00 \\
0,00 \\
0,00 \\
0,00 \\
0,00\end{array}$ & $\begin{array}{l}2,67 \\
3,00 \\
2,67 \\
2,67 \\
2,34 \\
2,01 \\
1,68 \\
2,01\end{array}$ & $\begin{array}{l}4,15 \\
5,17 \\
5,15\end{array}$ \\
\hline GP 1 & $\begin{array}{l}0-0,025 \\
0,025-0,05 \\
0,05-0,075 \\
0,075-0,10 \\
0,10-0,15 \\
0,15-0,20 \\
0,20-0,30 \\
0,30-0,40\end{array}$ & $\begin{array}{l}20,1 \\
23,6 \\
17,9 \\
16,7 \\
14,1 \\
13,6 \\
11,9 \\
10,3\end{array}$ & $\begin{array}{l}5,85 \\
5,60 \\
5,60 \\
5,75 \\
5,95 \\
6,15 \\
6,25 \\
6,25\end{array}$ & $\begin{array}{l}5,10 \\
4,80 \\
4,95 \\
5,20 \\
5,45 \\
5,60 \\
5,60 \\
5,50\end{array}$ & $\begin{array}{l}0,05 \\
0,05 \\
0,00 \\
0,00 \\
0,00 \\
0,00 \\
0,00 \\
0,00\end{array}$ & $\begin{array}{l}2,34 \\
3,33 \\
3,00 \\
2,01 \\
1,68 \\
2,01 \\
0,99 \\
1,68\end{array}$ & $\begin{array}{l}4,13 \\
4,95 \\
4,95\end{array}$ \\
\hline GP 2 & $\begin{array}{l}0-0,025 \\
0,025-0,05 \\
0,05-0,075 \\
0,075-0,10 \\
0,10-0,15 \\
0,15-0,20 \\
0,20-0,30 \\
0,30-0,40\end{array}$ & $\begin{array}{l}21,7 \\
28,0 \\
28,0 \\
24,3 \\
23,0 \\
22,7 \\
18,9 \\
17,4\end{array}$ & $\begin{array}{l}6,00 \\
5,90 \\
5,70 \\
5,80 \\
5,70 \\
5,85 \\
6,05 \\
5,15\end{array}$ & $\begin{array}{l}5,30 \\
5,20 \\
5,10 \\
5,25 \\
5,10 \\
5,30 \\
5,60 \\
4,60\end{array}$ & $\begin{array}{l}0,00 \\
0,00 \\
0,00 \\
0,00 \\
0,00 \\
0,00 \\
0,00 \\
0,05\end{array}$ & $\begin{array}{l}2,34 \\
3,00 \\
3,00 \\
2,67 \\
2,34 \\
2,34 \\
1,32 \\
2,34\end{array}$ & $\begin{array}{l}4,60 \\
4,50\end{array}$ \\
\hline
\end{tabular}


Quadro 3. Resultados das análises de cálcio, magnésio, potássio e soma de bases para as seis trincheiras estudadas

\begin{tabular}{|c|c|c|c|c|c|}
\hline Solo & Profundidade & $\mathrm{Ca}^{2+}$ & $\mathbf{M g}^{2+}$ & $\mathbf{K}^{+}$ & SB \\
\hline & $\mathrm{cm}$ & \multicolumn{4}{|c|}{$\mathrm{cmol}_{\mathrm{c}} \mathrm{dm}^{-3}$ de solo } \\
\hline CC & $\begin{array}{l}0-0,025 \\
0,025-0,05 \\
0,05-0,075 \\
0,075-0,10 \\
0,10-0,15 \\
0,15-0,20 \\
0,20-0,30 \\
0,30-0,40\end{array}$ & $\begin{array}{l}0,45 \\
0,22 \\
0,13 \\
0,14 \\
0,12 \\
0,10 \\
0,10 \\
0,22\end{array}$ & $\begin{array}{l}0,19 \\
0,02 \\
0,00 \\
0,00 \\
0,00 \\
0,00 \\
0,00 \\
0,00\end{array}$ & $\begin{array}{l}0,15 \\
0,11 \\
0,08 \\
0,06 \\
0,05 \\
0,03 \\
0,02 \\
0,03\end{array}$ & $\begin{array}{l}0,79 \\
0,35 \\
0,21 \\
0,20 \\
0,17 \\
0,13 \\
0,12 \\
0,26\end{array}$ \\
\hline$C P$ & $\begin{array}{l}0-0,025 \\
0,025-0,05 \\
0,05-0,075 \\
0,075-0,10 \\
0,10-0,15 \\
0,15-0,20 \\
0,20-0,30 \\
0,30-0,40\end{array}$ & $\begin{array}{l}1,58 \\
1,68 \\
1,41 \\
1,73 \\
1,67 \\
1,56 \\
1,36 \\
1,36\end{array}$ & $\begin{array}{l}0,25 \\
0,22 \\
0,17 \\
0,21 \\
0,24 \\
0,22 \\
0,20 \\
0,24\end{array}$ & $\begin{array}{l}0,29 \\
0,21 \\
0,22 \\
0,15 \\
0,12 \\
0,12 \\
0,10 \\
0,04\end{array}$ & $\begin{array}{l}2,12 \\
2,11 \\
1,80 \\
2,19 \\
2,03 \\
1,90 \\
1,66 \\
1,64\end{array}$ \\
\hline GC & $\begin{array}{l}0-0,025 \\
0,025-0,05 \\
0,05-0,075 \\
0,075-0,10 \\
0,10-0,15 \\
0,15-0,20 \\
0,20-0,30 \\
0,30-0,40\end{array}$ & $\begin{array}{l}0,26 \\
0,14 \\
0,13 \\
0,12 \\
0,13 \\
0,14 \\
0,08 \\
0,10\end{array}$ & $\begin{array}{l}0,02 \\
0,00 \\
0,00 \\
0,00 \\
0,00 \\
0,00 \\
0,00 \\
0,00\end{array}$ & $\begin{array}{l}0,06 \\
0,06 \\
0,06 \\
0,05 \\
0,05 \\
0,05 \\
0,03 \\
0,03\end{array}$ & $\begin{array}{l}0,34 \\
0,20 \\
0,19 \\
0,17 \\
0,18 \\
0,19 \\
0,11 \\
0,13\end{array}$ \\
\hline GPa & $\begin{array}{l}0-0,025 \\
0,025-0,05 \\
0,05-0,075 \\
0,075-0,10 \\
0,10-0,15 \\
0,15-0,20 \\
0,20-0,30 \\
0,30-0,40\end{array}$ & $\begin{array}{l}1,39 \\
1,06 \\
0,90 \\
0,94 \\
1,01 \\
0,92 \\
0,83 \\
0,89\end{array}$ & $\begin{array}{l}0,89 \\
0,49 \\
0,47 \\
0,18 \\
0,05 \\
0,01 \\
0,00 \\
0,00\end{array}$ & $\begin{array}{l}0,22 \\
0,16 \\
0,11 \\
0,09 \\
0,06 \\
0,06 \\
0,07 \\
0,03\end{array}$ & $\begin{array}{l}2,50 \\
1,71 \\
1,68 \\
1,21 \\
1,18 \\
0,99 \\
0,90 \\
0,92\end{array}$ \\
\hline GP1 & $\begin{array}{l}0-0,025 \\
0,025-0,05 \\
0,05-0,075 \\
0,075-0,10 \\
0,10-0,15 \\
0,15-0,20 \\
0,20-0,30 \\
0,30-0,40\end{array}$ & $\begin{array}{l}1,68 \\
1,67 \\
1,97 \\
2,25 \\
1,93 \\
1,99 \\
1,49 \\
1,07\end{array}$ & $\begin{array}{l}0,42 \\
0,22 \\
0,29 \\
0,42 \\
0,34 \\
0,44 \\
0,36 \\
0,29\end{array}$ & $\begin{array}{l}0,34 \\
0,22 \\
0,18 \\
0,18 \\
0,11 \\
0,14 \\
0,11 \\
0,11\end{array}$ & $\begin{array}{l}2,44 \\
2,11 \\
2,44 \\
2,85 \\
2,38 \\
2,57 \\
1,96 \\
1,47\end{array}$ \\
\hline GP2 & $\begin{array}{l}0-0,025 \\
0,025-0,05 \\
0,05-0,075 \\
0,075-0,10 \\
0,10-0,15 \\
0,15-0,20 \\
0,20-0,30 \\
0,30-0,40\end{array}$ & $\begin{array}{l}2,22 \\
2,34 \\
2,45 \\
2,35 \\
2,08 \\
2,23 \\
2,11 \\
1,33\end{array}$ & $\begin{array}{l}0,40 \\
0,61 \\
0,61 \\
0,70 \\
0,57 \\
0,63 \\
0,66 \\
0,30\end{array}$ & $\begin{array}{l}0,21 \\
0,21 \\
0,16 \\
0,07 \\
0,04 \\
0,03 \\
0,03 \\
0,08\end{array}$ & $\begin{array}{l}2,83 \\
3,17 \\
3,23 \\
3,12 \\
2,69 \\
2,89 \\
2,80 \\
1,61\end{array}$ \\
\hline
\end{tabular}

a grande quantidade de raízes presentes neste solo, além do que esta MORG, por ser de gramínea, apresenta-se mais humificada. Com isto, o efeito de melhoria física provocado pela MORG sobrepôs-se às modi ficações químicas promovidas pel o uso do solo.

O PCZ revelou comportamento diferente nos locais estudados. Observando o quadro 2, nota-se que, para as trincheiras CC, CP e GC, os valores de PCZ praticamente não variaram dentro das trincheiras, ou seja, não acompanharam os teores de MORG. J á para os outros três locais, GPa, GP1,
GP2, os valores de PCZ aumentaram ao longo da trincheira de maneira clara, tendo, neste caso, possivelmente, uma correlação negativa e significativa com a MORG. Tal variação, no entanto, foi insuficientepara dar uma correlação significativa entre MORG e PCZ, possivelmente pela natureza dessa matéria orgânica que pode estar influenciando mais que sua quantidade.

O PCZ teve correlação negativa e significativa a $1 \%$ com a acidez trocável e a potencial. Os coeficientes decorrelação foram de-0,6113e-0,5733, respectivamente, ou seja, o aumento do $\mathrm{Al}^{3+}$ e do $\mathrm{H}+\mathrm{Al}$ diminuiu o PCZ.

Em relação aos resultados de ataque sulfúrico (Quadro 5), observa-se que, ao longo das trincheiras, ocorreu um aumento dos teores dos óxidos analisados em profundidade, acompanhando a descida de argila, com exceção do $\mathrm{P}_{2} \mathrm{O}_{5}$, que apresentou maiores teores na superfície, já que tem como principal fonte a adubação. Pode-se observar isto comparando-se os maiores teores nos sol os cultivados em relaçãoàqueles sob vegetação natural. Os óxidos de Al, Fe eTi não variaram de maneira consistente com o cultivo.

Com relação à formação das camadas adensadas e, ou, compactadas, apenas o $\mathrm{SiO}_{2}$ teve correlação significativa com al gumas variáveis importantes na formação destas. O coeficiente de correl ação do $\mathrm{SiO}_{2}$ com a densidade do solo foi de 0,4152 , significativo

Quadro 4. Resultados dos coeficientes de correlação e níveis de significância da argila dispersa em água (ARGD) e densidade do solo (DSOL) com pH em água, pH em $\mathrm{KCl}$, acidez trocável, potencial, $\mathrm{Ca}^{2+}, \mathrm{Mg}^{2+}, \mathrm{K}^{+}$e soma de bases (SB) para as seis trincheiras estudadas

\begin{tabular}{|c|c|}
\hline Correlação & Coeficiente de Correlação \\
\hline ARGD/pH H $\mathrm{H}_{2} \mathrm{O}$ & $0,2963^{*}$ \\
\hline ARGD/pH KCl & $0,3761^{* *}$ \\
\hline ARGD/acidez trocável & $-0,3680 * *$ \\
\hline ARGD/acidez potencial & $-0,4050 * *$ \\
\hline $\mathrm{ARGD} / \mathrm{Ca}^{2+}$ & $0,5545^{* *}$ \\
\hline ARGD/Mg ${ }^{2+}$ & $0,3500^{* *}$ \\
\hline $\mathrm{ARGD} / \mathrm{K}^{+}$ & $0,1370^{\text {ns }}$ \\
\hline ARGD/SB & $0,4996 * *$ \\
\hline $\mathrm{DSOL} / \mathrm{pH} \mathrm{H} \mathrm{H}_{2} \mathrm{O}$ & $0,3806 * *$ \\
\hline $\mathrm{DSOL} / \mathrm{pH} \mathrm{KCl}$ & $0,4578^{* *}$ \\
\hline DSOL/acidez trocável & $-0,3956 * *$ \\
\hline DSOL/acidez potencial & $-0,3334 *$ \\
\hline $\mathrm{DSOL} / \mathrm{Ca}^{2+}$ & $0,6635^{* *}$ \\
\hline $\mathrm{DSOL} / \mathrm{Mg}^{2+}$ & $0,3764^{* *}$ \\
\hline $\mathrm{DSOL} / \mathrm{K}^{+}$ & $0,1580^{\text {ns }}$ \\
\hline DSOL/SB & $0,5964^{* *}$ \\
\hline
\end{tabular}


Quadro 5. Resultados das análises de ataque sulfúrico para $\mathrm{Fe}_{2} \mathrm{O}_{3}, \mathrm{Al}_{2} \mathrm{O}_{3}, \mathrm{SiO}_{2}, \mathrm{TiO}_{2}$ e $\mathrm{P}_{2} \mathrm{O}_{5}$ para as seis trincheiras estudadas

\begin{tabular}{|c|c|c|c|c|c|c|}
\hline Solo & Profundidade & $\mathrm{Fe}_{2} \mathrm{O}_{3}$ & $\mathrm{Al}_{2} \mathrm{O}_{3}$ & $\mathrm{SiO}_{2}$ & $\mathrm{TiO}_{2}$ & $\mathbf{P}_{2} \mathbf{O}_{5}$ \\
\hline & $\mathrm{m}$ & & $-g k$ & $y^{-1}$ de & 10 & \\
\hline \multirow[t]{3}{*}{$\mathrm{CC}$} & $\begin{array}{l}0-0,025 \\
0,025-0,05 \\
0,05-0,075\end{array}$ & $\begin{array}{l}32,5 \\
36,0\end{array}$ & $\begin{array}{l}68,2 \\
79,6\end{array}$ & $\begin{array}{l}52,0 \\
56,4\end{array}$ & $\begin{array}{l}6,3 \\
7,4\end{array}$ & $\begin{array}{l}0,9 \\
0,8\end{array}$ \\
\hline & $\begin{array}{l}0,075-0,10 \\
0,10-15 \\
0,15-0,20\end{array}$ & 36,5 & 87,6 & 64,2 & 7,4 & 0,8 \\
\hline & $\begin{array}{l}0,20-0,30 \\
0,30-0,40\end{array}$ & 40,5 & 104,2 & - & 8,8 & 0,8 \\
\hline \multirow[t]{3}{*}{$C P$} & $\begin{array}{l}0-0,025 \\
0,025-0,05\end{array}$ & 43,5 & 60,8 & 46,0 & 11,2 & 1,6 \\
\hline & $\begin{array}{l}0,075-0,10 \\
0,10-0,15\end{array}$ & 45,0 & 65,4 & 47,2 & 12,1 & 1,1 \\
\hline & $\begin{array}{l}0,15-0,20 \\
0,20-0,30 \\
0,30-0,40\end{array}$ & 47,5 & 76,5 & 53,2 & 12,0 & 0,9 \\
\hline \multirow[t]{3}{*}{$\mathrm{GC}$} & $\begin{array}{l}0-0,025 \\
0,025-0,05\end{array}$ & 37,0 & 55,1 & 49,4 & 9,4 & 0,8 \\
\hline & $\begin{array}{l}0,05-0,075 \\
0,075-0,10 \\
0,10-0,15 \\
0,15-0,20\end{array}$ & 40,5 & 64,6 & 60,6 & 11,4 & 0,7 \\
\hline & & 42,5 & 69,5 & 62,2 & 11,0 & 0,6 \\
\hline \multirow[t]{3}{*}{ GPa } & $0-0,025$ & 40,5 & 65,8 & 42,6 & 12,2 & 1,5 \\
\hline & $\begin{array}{l}0,05-0,075 \\
0,075-0,10 \\
0,10-0,15 \\
0,15-0,20\end{array}$ & 43,0 & 65,8 & 34,8 & 12,2 & 1,1 \\
\hline & $\begin{array}{l}0,20-0,30 \\
0,30-0,40\end{array}$ & 42,5 & 68,6 & 41,8 & 12,4 & 0,8 \\
\hline \multirow[t]{3}{*}{ GP 1} & $0-0,025$ & 39,5 & 64,0 & 52,6 & 10,0 & 1,9 \\
\hline & $\begin{array}{l}0,05-0,075 \\
0,075-0,10 \\
0\end{array}$ & 38,0 & 63,7 & 48,6 & 9,3 & 1,9 \\
\hline & $\begin{array}{l}0,15-0,20 \\
0,20-0,30 \\
0,30-0,40\end{array}$ & 41,5 & 71,9 & 67,2 & 11,1 & 0,9 \\
\hline \multirow[t]{3}{*}{ GP2 } & $\begin{array}{l}0-0,025 \\
0,025-0,05\end{array}$ & $\begin{array}{l}32,5 \\
34,0\end{array}$ & $\begin{array}{l}74,0 \\
74,4\end{array}$ & $\begin{array}{l}68,8 \\
71,0\end{array}$ & $\begin{array}{l}7,0 \\
7,6\end{array}$ & $\begin{array}{l}1,4 \\
1,6\end{array}$ \\
\hline & $\begin{array}{l}0,075-0,10 \\
0,10-0,15 \\
0,15-0,20\end{array}$ & 34,0 & 77,1 & 64,2 & 7,9 & 1,3 \\
\hline & & 35,5 & 74,2 & 67,0 & 8,8 & 0,7 \\
\hline
\end{tabular}

a $5 \%$. A explicação para este efeito pode ser dada pela correl ação $(0,6091)$ significativa a $1 \%$, que teve o $\mathrm{SiO}_{2}$ com argila dispersa em água. $\mathrm{O} \mathrm{SiO}_{2}$ podeter contribuído com aumento de carga negativa do solo e, conseqüentemente, com aumento da argila dispersa em água.

Observou-se que o cultivo trouxe grandes mudanças em alguns atributos químicos dos solos, em relação ao ambiente natural, que estaria em determinado equilíbrio, provocando também mudanças em seus atributos físicos, principal mente na formação das camadas compactadas e, ou, adensadas. De maneira menos drástica, mas consistente, observaram-se tais mudanças também nos solos sob vegetação natural. Algumas dessas propriedades estudadas podem ser importantes para prever o comportamento desses solos, quando submetidos ao cultivo.

Há necessidade de mais estudos sobrea formação das camadas compactadas e, ou, adensadas, principalmente relacionados com aspectos mineralógicos, formação de amorfos de silício, ferro e alumínio, complexos organo-minerais, além de aprofundar-se nos aspectos físico-químicos do solo.

\section{CONCLUSÕES}

1. Com o aumento da argila dispersa em água, nos solos cultivados, houve um favorecimento de formação das camadas adensadas em subsuperfície.

2. Modificações químicas provocadas pelo cultivo, principalmente com relação à acidez do solo, causaram problemas nas propriedades físicas, efetivamente no que se refere ao aumento da argila dispersa em água.

3. O teor de $\mathrm{SiO}_{2}$ afetou diretamentea densidade do solo, por meio de seu efeito direto na argila dispersa em água.

\section{LITERATURA CITADA}

ALVARENGA, R.C.; CRUZ, J.C. \& PACHECO, E.B. Preparo do solo. Inf. Agropec., 13:40-45, 1987.

BAVER, L.D.; GARDNER, W.H. \& GARDNER, W.R. Física de suelos. Buenos Aires, Centro Regional de Ayuda Tecnica, 1973. 529p.

COSTA, L.M.; MORAIS, E.J.; RIBEIRO, A.C. \& FONSECA, S. Cargas elétricas de um Latossolo Vermel ho Amarelo com diferentes coberturas florestais. R. Ceres, 31:351-359, 1984.

DEFELIPO, B.V. \& RIBEIRO, A.C. Análise química do solo: metodologia. Viçosa, U niversidade Federal deViçosa, 1981. 17p. (Boletim de Extensão, 29)

ELTZ, F.L.F.; PEIXOTO, R.T.G. \& J ASTER, F. Efeitos de sistemas de preparo do solo nas propriedades físicas e químicas de um Latossolo Bruno álico. R. Bras. Ci. Solo, 13:259-267, 1989.

EMPRESA BRASILEIRA DE PESQUISA AGROPECUÁRIAEMBRAPA. Serviço Nacional de Levantamento e Conservação de Solos. Manual de métodos de análise de solo. Rio de J aneiro, 1979. não paginado.

FARIAS, C.A.; COSTA, L.M. \& FONTES, L.E.F. Determinação do número de repetições necessárias para análise de argila dispersa em água. R. Ceres, 38:505-512, 1991. 
FERNANDES, R.B.A. Influência das características químicas, físicas e mineralógicas na compactação de três Latossolos. Viçosa, Universidade Federal de Viçosa, 1996. 117p. (Tese de Mestrado)

FONSECA, O.M. Caracterização e classificação de solos latossólicos e podzólicos desenvolvidos nos sedimentos do terciário no litoral brasileiro. I taguaí, U niversidade Federal Rural do Rio de J aneiro, 1986. 185p. (Tese de Mestrado)

GOMES, T.C.A. Análise de trilha no estudo de fatores físicos e quími cos relacionados ao adensamento e, ou, à compactação em dois solos do Norte de Minas Gerais. Viçosa, Universidade Federal de Viçosa, 1996. 105p. (Tese de Mestrado)

J UCKSCH, I. Calagem e dispersão de argila em amostra de um Latossolo Vermel ho-Escuro. Viçosa, Universidade Federal de Viçosa, 1987. 37p. (Tese de Mestrado)

MANTOVANI, E.C. Compactação do solo. Inf. Agropec., 13:52$55,1987$.
OLIVEIRA, T.S. Efeitos dos ciclos de umedecimento e secagem sobre propriedades físicas e químicas de quatro Latossolos brasileiros. Viçosa, Universidade Federal de Viçosa, 1992. 104p. (Tese de Mestrado)

PALADINI, F.L.S. \& MIELNICZUK, J. Distribuição de tamanho de agregados de um sol o Podzól ico Vermel ho-Escuro afetado por sistemas de culturas. R. Bras. Ci. Solo, 15:135-140, 1991.

RAIJ , B. van; QUAGGIO, J.A.; CANTARELLA, H.; FERREIRA, M.E.; LOPES, A.S. \& BATAGLIA, O.C. Análise química do solo para fins de fertilidade. Campinas, Fundação Cargill, 1981. 170p.

ROTH, C.H.; CASTRO FILHO, C. \& MEDEIROS, G.B. Análise de fatores físicos e químicos relacionados com agregação de um Latossolo Roxo distrófico. R. Bras. Ci. Solo, 15:241248, 1991.

VETTORI, L. Métodos de análise de solos. Brasília, EPE. Ministério da Agricultura, 1969. 24p. (Boletim técnico, 7) 